\title{
SAÚDE E SAÚDE MENTAL NA PERCEPÇÃO DE TRABALHADORES DE UM CAPSi
}

\author{
HEALTH AND MENTAL HEALTH IN THE VIEW OF THE WORKERS OF A CAPSi
}

SALUD Y SALUD MENTAL EN LA PERCEPCIÓN DE TRABAJADORES DE UN CAPSi

\author{
Juliane Caeran ${ }^{1}$ \\ Hericka Zogbi Jorge Dias ${ }^{2}$
}

Resumo Este artigo trata de um estudo prospectivo e descritivo de abordagem qualitativa que investigou, por meio de grupo focal, as percepções que os trabalhadores de um Centro de Atenção Psicossocial Infantojuvenil, o CAPSi, no interior do Rio Grande do Sul, Brasil, têm sobre saúde e saúde mental. O referencial teórico baseia-se na psicodinâmica do trabalho de Christophe Dejours, nas políticas e diretrizes do Ministério da Saúde e nos conceitos de saúde e saúde mental propostos pela Organização Mundial da Saúde. O material foi analisado por codificação temática, com base na abordagem da estrutura. Como principais resultados, destacam-se a capacidade de resolver situações conflitivas e a realização de alguma atividade corporal como estratégias de manutenção da saúde e da saúde mental, bem como a compreensão integrada de saúde entre aspectos físicos, psíquicos e sociais.

Palavras-chave saúde; saúde mental; saúde mental do trabalhador; CAPSi.
Abstract This article is a prospective, descriptive study using a qualitative approach that investigated, through focus groups, the views that the employees of a Psychosocial Care Center for Children and Adolescents, CAPSi, in the interior of the state of Rio Grande do Sul, Brazil, have on health and mental health. The theoretical framework is based on Christophe Dejours' work psychodynamics, on the policies and guidelines of the Ministry of Health, and on the concepts of health and mental health proposed by the World Health Organization. The material was analyzed using theme coding based on approach made of the structure. The main results include the ability to resolve conflict situations and to undertake some bodily activity as strategies to maintain health and mental health, in addition to the integrated understanding of health, including physical, psychological, and social aspects.

Keywords health; mental health; mental health worker; CAPSi. 


\section{Introdução}

Conforme dados do Ministério da Saúde (Brasil, 2005), estima-se que 3\% da população necessita de cuidados em saúde mental, devido a transtornos mentais severos e persistentes. Além disso, entre 10 a $12 \%$ da população necessita de cuidados por transtornos mentais moderados e leves. Desse modo, a saúde mental exige a construção de uma rede de cuidados densa, diversificada e resolutiva, na qual se incluem os Centros de Atenção Psicossocial, os CAPS (Brasil, 2005).

Os CAPS são serviços de atenção psicossocial destinados ao tratamento diário de pessoas portadoras de transtornos mentais severos ou persistentes. As atividades neles realizadas incluem: atendimento individual (medicamentoso, psicoterápico, de orientação, entre outros); atendimento em grupo (psicoterapia, grupo operativo, atividades de suporte social, entre outros); atendimento em oficinas terapêuticas; visitas e atendimentos domiciliares; atendimento à família; atividades comunitárias enfocando a integração social do usuário (Brasil, 2002).

Uma modalidade de CAPS é o Centro de Atenção Psicossocial Infantojuvenil (CAPSi), que realiza atenção em saúde mental para crianças e adolescentes com transtornos mentais graves. Além disso, o centro se relaciona diretamente com a família, a escola e a comunidade em que o usuário está inserido, bem como mantém contato com outros serviços das áreas de assistência social, educação e justiça (Brasil, 2002).

A equipe técnica mínima do CAPSi é composta por médico psiquiatra, ou neurologista, ou pediatra com formação em saúde mental; enfermeiro; profissionais de nível superior, como psicólogo, assistente social, enfermeiro, terapeuta ocupacional, fonoaudiólogo, pedagogo; e profissionais de nível médio, como técnico ou auxiliar de enfermagem, técnico administrativo, técnico educacional e artesão (Brasil, 2002).

A dinâmica de trabalho no CAPS se orienta pelo trabalho em equipe interdisciplinar e pela clínica ampliada, os quais abrem possibilidades para a redefinição e a qualidade do trabalho em saúde e saúde mental, bem como para a articulação e a inclusão entre os vários saberes. Ambos resgatam o compromisso com o sujeito, na medida em que reconhecem a complexidade do processo de adoecimento, não 'recortando' o sujeito em partes ou patologias como muitas vezes se observa quando os saberes profissionais se encontram separados (Brasil, 2009).

O campo da saúde e da saúde mental é marcado por muitos desafios. Há diferentes estudos (Campos e Soares, 2003; Sessa et al., 2008; Silva e Costa, 2008; Santos e Cardoso, 2010) que vêm apontando para a necessidade crescente de atenção à saúde dos trabalhadores, em especial aqueles da área de saúde e saúde mental, em virtude da forte carga emocional a que estão sub- 
metidos diariamente. Uma forma de aproximação aos trabalhadores ocorre por meio da atividade em grupo, na qual há espaço para discussão e reflexão sobre percepções e práticas que fazem parte de seu cotidiano.

Desse modo, neste artigo serão apresentados os resultados de um trabalho com grupo focal que envolveu trabalhadores da área de saúde mental infantil, especificamente de CAPSi, buscando investigar as percepções que esses trabalhadores têm sobre saúde e saúde mental. Para tratar dessas questões, tomamos por base conceitual a psicodinâmica do trabalho de Christophe Dejours (1994, 1992 e 1994), reconhecido pela importância de sua obra sobre a organização do trabalho e os efeitos desta na saúde mental do trabalhador. Também nos baseamos nos conceitos de saúde e saúde mental propostos pela Organização Mundial da Saúde (OMS) (World Health Organization, 2005) e nas políticas e diretrizes sobre saúde mental do Ministério da Saúde (Brasil, 2002, 2004, 2005 e 2009).

Segundo Hennington (2008), o trabalho em saúde mental infantil exige o uso das capacidades físicas e psíquicas, intelectuais e emocionais, a troca de afetos e de saberes; impõe a convivência diária com inúmeras formas de sofrimento e com as implicações do processo saúde e da doença, as quais causam inevitáveis efeitos no corpo e na mente. Assim, considerando que o trabalhador em saúde mental tem a seu cargo uma vasta demanda de sofrimentos psíquicos, acreditamos ser importante conhecer as percepções que ele tem sobre saúde e saúde mental, visto que elas permeiam e orientam o seu campo de trabalho - o CAPSi.

\section{Saúde, saúde mental e qualidade de vida}

Os conceitos de saúde e de doença possuem evolução histórica e entendem a saúde como grande meta a ser alcançada. No decorrer dos séculos, muitas foram as transformações pelas quais passou o conceito de saúde, destacando-se o enfoque biomédico como influência predominante desse conceito. Contudo, atualmente a saúde já não vem sendo enfocada exclusivamente pela ótica das ciências biológicas, mas comporta uma visão ampliada, interdisciplinar (Scliar, 2007; Brasil, 2009). A nova definição de saúde considera, para além da doença, a dimensão biopsicossocial e o indivíduo integrado ao ambiente do qual faz parte. Saúde, doença e corpo não são fatores isolados, mas sim um todo interligado (Scliar, 2007; Buss e Pellegrini Filho, 2007; Brasil, 2009). O modelo biopsicossocial considera que a saúde e outros comportamentos são determinados pela interação de mecanismos biológicos, processos psicológicos e influências sociais (Straub, 2005).

Considerando esses aspectos, a OMS define o conceito de saúde como um "estado de completo bem-estar físico, mental e social e não meramente a 
ausência de doença ou enfermidade" (World Health Organization, 2005, p. 2, tradução nossa). ${ }^{3}$ Além disso, afirma que a maioria das doenças mentais e físicas sofre influência de uma combinação de fatores biológicos, pscológicos e sociais. Logo, saúde mental, física e social se encontram interligadas, ficando cada vez mais evidente que a saúde mental é indispensável ao bem-estar dos indivíduos e necessita de atenção. Com base nisso, considera também que a saúde mental, além da ausência de transtorno mental, pode ser definida como um estado de bem-estar no qual o indivíduo consegue exercer seu potencial, lidar com o estresse normal da vida, trabalhar e exercer a vida social.

Outra consideração importante diz respeito à qualidade de vida e à forma como o sujeito a percebe, interferindo de forma positiva ou negativa na sua saúde e na sua saúde mental. A qualidade de vida é definida, pela OMS, como "percepção do indivíduo de sua posição na vida, no contexto da cultura e sistema de valores nos quais ele vive e em relação aos seus objetivos, expectativas, padrões e realizações" (Fleck et al., 2000, p. 179).

\section{Percurso metodológico}

O estudo aqui tratado foi prospectivo e descritivo, de abordagem qualitativa. ${ }^{4} \mathrm{O}$ referencial teórico-metodológico utilizado foi o da pesquisa qualitativa, que possibilita conhecer em profundidade a realidade investigada, estudar as comunicações e relações humanas em seus ambientes naturais e considerar a complexidade do humano, a qual, muitas vezes, limita-se a fatos objetivos mensuráveis. Ressalta-se, porém, que a pesquisa qualitativa e a quantitativa não são métodos opostos, mas sim complementares (Pope e Mays, 2006; Minayo, 2007; Gibbs, 2009; Flick, 2009).

O estudo realizou-se em um CAPSi de uma cidade do interior do Rio Grande do Sul. Foram convidados a participar os 15 trabalhadores desse centro. Dos 15, quatro optaram por não participar e um se desligou do serviço antes da realização do grupo. O critério de exclusão adotado foi não possuir vínculo empregatício com o local.

A coleta dos dados foi realizada por meio da atividade de grupos focais. O grupo focal é um instrumento qualitativo de pesquisa que privilegia a comunicação, a interação, os questionamentos, as trocas de conhecimento e os relatos de experiência entre os participantes da pesquisa, de modo a gerar dados e insights sobre determinado assunto (Flick, 2009; Kitzinger, 2006). A realização de discussões em grupo é especialmente adequada quando o pesquisador se utiliza de perguntas abertas e almeja estimular os participantes a explorarem assuntos relevantes para eles; pretende construir uma análise, baseada nas experiências comuns, entre os membros e possibilitar o debate sobre temas relacionados ao grupo (Kitzinger, 2006). 
Os grupos focais desenvolvidos neste estudo caracterizaram-se por ser abertos e heterogêneos quanto às profissões, e se realizaram em três encontros quinzenais, com duração aproximada de duas horas. Os encontros ocorreram nas dependências do CAPSi, antes da reunião semanal de equipe, conforme a decisão do grupo, no período de julho a agosto de 2011. A característica de grupo aberto se deu para que os membros pudessem participar de qualquer número de encontros conforme sua disponibilidade e interesse. Os encontros foram gravados em áudio, para fins de registro, a partir da concordância dos membros.

A análise do material obtido ocorreu por codificação temática, com base na abordagem da estrutura (Pope, Ziebland e Mays, 2006; Flick, 2009), visando conhecer as percepções sobre saúde e saúde mental que os referidos trabalhadores apresentam. Os procedimentos realizados de acordo com Pope, Ziebland e Mays (2006) consistiram na identificação inicial das estruturas temáticas principais através de sucessivas leituras, por meio das quais os dados pudessem ser analisados e referenciados. Isso foi feito pela utilização de questões oriundas dos objetivos do estudo, bem como por tópicos levantados pelos participantes e por experiências ou visões que se repetem nos dados, originando-se, assim, um detalhado índice de dados.

Em seguida, procedeu-se à indexação, que consiste em aplicar o índice temático de forma sistemática a todos os dados textuais. Usualmente, uma única passagem do texto pode conter vários temas diferentes. Após essa etapa, realizou-se o mapeamento, ou seja, a reorganização e a correlação dos temas com a construção de registros gráficos. Por fim, mediante registros gráficos, realizou-se a interpretação do material. Esse processo é influenciado pelos objetivos da pesquisa e também pelos temas que emergiram dos próprios dados.

O projeto da pesquisa recebeu aprovação do Comitê de Ética em Pesquisa da Universidade Federal de Santa Maria, de acordo com o Certificado de Apresentação para Apreciação Ética (CAAE 0133.0.243.000-11). Os nomes dos participantes foram substituídos pela letra “ $\mathrm{T}$ ", de trabalhador, seguida de um número, de modo a preservar a identidade dos sujeitos.

\section{Apresentação e discussão dos resultados}

Todos os participantes eram mulheres, com idade média de 38 anos. Quanto às profissões, os grupos tiveram a presença de psicóloga, fisioterapeuta, técnica em saúde mental, enfermeira, arteterapeuta, assistente social e educadora física.

Apresentaremos neste trabalho as informações referentes aos temas "Saúde na percepção dos trabalhadores" e "Saúde mental na percepção dos 
trabalhadores". Cada um desses temas teve seu conteúdo subdividido para melhor se relacionar e interpretar os dados. Observamos que o principal conector entre temas de saúde e saúde mental foi 'equilíbrio' como meio que permite a resolução de situações conflitivas e a manutenção da saúde e da saúde mental. A estrutura temática resultante é apresentada na Figura 1.

Figura 1

Estrutura temática resultante dos temas "Saúde na percepção dos trabalhadores" e "Saúde mental na percepção dos trabalhadores"

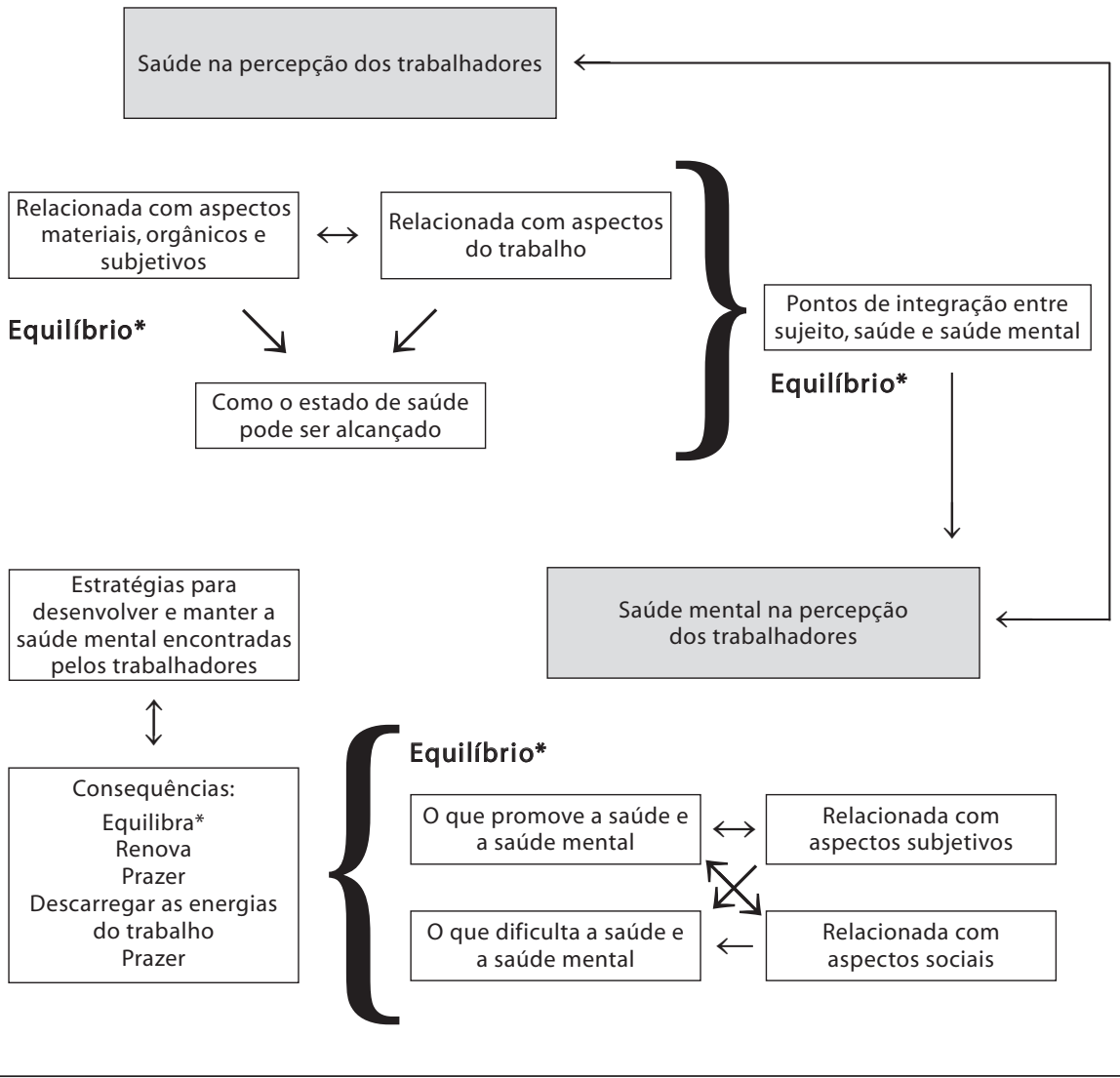

Fonte: Os autores.

${ }^{*}$ ) Conector

O tema denominado "Saúde na percepção dos trabalhadores", apresentado na sequência, trata das percepções que os trabalhadores apresentam sobre o que é saúde e como ela pode ser alcançada. 


\section{Aspectos materiais, orgânicos e subjetivos da saúde}

Primeiramente a saúde foi entendida pelos trabalhadores como estando relacionada às condições materiais, as quais possibilitarão o acesso à boa qualidade de vida, lazer, habitação e trabalho. Do mesmo modo, proporcionarão o atendimento das necessidades básicas, entendidas como moradia, alimentação e trabalho.

Bom, quando eu falo em saúde ou penso em saúde, eu a relaciono com acesso, desde acesso a ter uma boa qualidade de vida, acesso a lazer, acesso a habitação, acesso a trabalho; então, para mim, está relacionada com essas questões (T16).

Como levar a vida... se tu não tens condições básicas de sobrevivência, não é? (T02).

Eu só consigo me sentir bem se eu tenho condições para isso. Para mim, vêm primeiro as condições materiais disso... (T16).

Somando-se às questões materiais, a saúde também foi referenciada pelos trabalhadores em seu aspecto subjetivo. Nesse sentido, apresentaram a noção de sujeito para além do campo material e orgânico, contudo viabilizado por esse, ou seja, o sentir-se bem depende de condições materiais, mas também de condições psíquicas. Assim, saúde aparece associada pelos trabalhadores com qualidade de vida, bem-estar, lazer, equilíbrio, condições dignas e ser saudável.

A primeira coisa que vem na cabeça, saúde é se sentir bem na vida e com os outros, assim, a primeira coisa que eu penso, antes de condições, ou, no caso, ao não ter doença. Primeiramente acho que é se sentir bem, assim, estar bem, ser saudável (T05).

Penso que tem a ver com tudo o que a gente falou, tem a ver com acesso. Bom, se eu tenho algo físico ou psicológico, que seja, ter acesso, poder ter o tratamento. Ter equilíbrio, como a T08 falava (...) (T01).

Sabe-se que a compreensão biomédica na qual a saúde está relacionada com a ausência de doença foi por muito tempo vigente nos serviços de saúde (Brasil, 2009). Contudo, ainda que em alguns momentos os trabalhadores relacionem saúde e manifestação de doença orgânica, muito maior foi a aproximação deles com noção de que saúde não se resume à questão orgânica ou necessariamente à ausência de doença. Assim, a compreensão de saúde e saúde mental como uma integração entre os campos físicos, psíquicos e 
sociais (World Health Organization, 2005) permite ao profissional de saúde ou da saúde mental nova perspectiva de relação, tratamento e atenção ao usuário. Além disso, apropriar-se dessa concepção implica refletir sobre sua própria condição de integração entre saúde e saúde mental e como isso se manifesta em suas ações cotidianas.

Eu até comentei que, ao se falar de doença, pensa-se na doença, na própria doença, mas claro que não é só isso. Só que, como eu disse, para mim saúde é se sentir bem, é estar bem (T05).

Os participantes também fazem menção à qualidade de vida, bem-estar, ser saudável, numa aproximação com os conceitos de saúde e qualidade de vida da OMS. Parece haver uma compreensão da saúde como processo subjetivo e dinâmico entre físico, psíquico e social, do qual resulta o bem-estar. Nesse sentido, Straub (2005) esclarece que a saúde física está relacionada com um corpo livre de doenças e vigoroso; a saúde psicológica envolve capacidade de resolução de problemas, estabilidade emocional e bem-estar; a saúde social compreende as relações interpessoais significativas, família, educação e cultura.

Compreendemos com isso que bem-estar envolve aspectos de personalidade, aspirações, desejos e valores, todos permeados pela cultura e pelo social. Desse modo, ainda que possa haver pontos em comum sobre o que seja bem-estar, ele também contém grande parcela de subjetividade. Tal fato pode ser observado no campo do trabalho, quando a mesma função é desempenhada com satisfação por uns e com sofrimento por outros. Nesse sentido, o sentir-se bem ou o bem-estar relaciona-se com qualidade de vida, visto que, segundo Fleck et al. (2000), a qualidade de vida envolve além do físico, psíquico e social, a percepção de si, do contexto de vida, do ambiente e as crenças pessoais.

\section{Aspectos do trabalho na saúde}

No que diz respeito ao trabalho, o grupo refere-se à parte social, ao sentir-se bem com os outros, à noção de que o trabalho tem influência no estado de saúde, assim como é influenciado por ele, e que a qualidade das profissões é o que permite às pessoas terem perspectivas.

E não só o fator do problema em si, a questão orgânica em si, ter saúde é ter uma qualidade de vida, lazer, habitação (...). A parte social, é lazer; o trabalho, acho que influencia a vida da gente também, é tudo, se você não está bem lá fora, isso se reflete aqui dentro; se você não está bem no trabalho, isso se reflete lá fora (T02). 
Concordo com as gurias sobre a qualidade de vida como a qualidade das profissões, porque isso permite dar condições para as pessoas terem expectativa, padrões de vida, porque eu noto, não só na saúde, mas também na educação, como a falta de uma boa perspectiva abala e afeta a saúde das pessoas (T04).

No que diz respeito ao campo social do trabalho, Dejours afirma que as exigências da organização do trabalho e as exigências do psiquismo do trabalhador são, muitas vezes, forças em conflito. Desse conflito resulta o sofrimento e os mecanismos defensivos contra ele. Quando há um desequilíbrio nessa estruturação, irrompendo o sofrimento que não mais pode ser conciliado, é, então, que se abre campo para o adoecimento (Dejours, 1994; Dejours e Abdoucheli, 1994).

Cabe aqui destacar que, de acordo com Brant e Minayo-Gomez (2004), o sofrimento não se manifesta nem é sentido da mesma forma por todos os indivíduos. Mesmo estando em idênticas condições ambientais, o que pode ser sofrimento para alguns não o será para outros, podendo ser, inclusive, motivo de prazer. Isso se deve ao fato de que o sofrimento depende da significação que o sujeito lhe atribui, conforme sua história. O que se manifesta dependerá da forma como será expresso, ou seja, da linguagem que nomeia aquilo que se sente por sofrimento, dor, prazer ou satisfação. É nesse sentido que Dejours (1992) adverte que o sofrimento nem sempre resulta em adoecimento, mas pode abrir espaço para a criatividade, dado que o trabalho também é responsável pelo prazer e pela realização pessoal. Seja qual for o resultado, o autor compreende que o trabalho nunca é neutro, favorecendo a saúde ou a doença.

\section{Como alcançar o estado de saúde}

Os trabalhadores entendem que o estado de saúde pode ser alcançado por meio da integração física, psíquica e social. O físico contempla atenção plena das necessidades básicas, acesso e tratamento físico ou psicológico. O psíquico foi relacionado com o equilíbrio e a singularidade, com uma busca singular e também coletiva. O social esteve ligado à mobilização social, entendida como essencial para o campo da saúde.

Eu acho que mobilização social para saúde é fundamental. Porque assim, se não fosse uma mobilização social, a gente não tinha até conquistado uma reunião de equipe, se não fossem os movimentos sociais, mobilização social não ia ter SUS. E até essa concepção de saúde que a gente traz, ela também veio de uma construção (T16).

Nesse sentido, Campos e Soares (2003) ressaltam que o desafio para a formulação de práticas no campo da saúde e da saúde mental é compreender 
que a saúde mental está intimamente ligada ao âmbito social. É necessário resgatar no ensino, e nos próprios serviços, os conceitos sobre saúde-doença mental que deram origem ao movimento de reforma psiquiátrica.

\section{Pontos de integração entre sujeito, saúde e saúde mental}

Inicialmente a questão da saúde esteve, de forma clara, focada nas condições materiais. Contudo, com o avanço da discussão e dos questionamentos, podemos observar no grupo uma tendência à integração dos aspectos que compõem o estado de saúde e saúde mental. Os participantes apresentaram a noção de saúde como composto que envolve vários aspectos. Por isso, é difícil separar saúde física e saúde mental.

A saúde é um composto, não é uma coisa única, assim... É isso que eu penso. Nós não estamos separados, eu penso assim (...) agora, eu sou a profissional T02 e lá fora sou... né? Tu és um contexto, um ser único. Então, saúde é estar bem em todos esses aspectos (T02).

Então, esse equilíbrio a gente tem de buscar para que a gente consiga sair bem nas várias situações da vida... até de ficar doente; muitas vezes, quando a gente está doente, o sofrimento mental acontece (T02).

Nesse sentido, o Ministério da Saúde (Brasil, 2005), no documento Reforma psiquiátrica e política de saúde mental no Brasil, destaca a importância da integralidade na atenção à saúde, ou seja, que saúde mental refere-se ao atendimento integral à pessoa e não apenas aos seus aspectos de doença. Assim, "todo problema de saúde é também - e sempre - de saúde mental, e que toda saúde mental é também - e sempre - produção de saúde" (Brasil, 2005, p. 33).

Por tal razão, o Ministério da Saúde (Brasil, 2009) defende que, ao se pensar a clínica, é necessário que se vá além de um único profissional, de um remédio ou de um exame, uma vez que as pessoas não se limitam à doença da qual são portadoras. A clínica ampliada convida o profissional a desenvolver a capacidade de ir além da doença, que o limite imposto ao sujeito pela doença não o impeça de desenvolver habilidade, pois a complexidade dos sujeitos que buscam os serviços de saúde não pode ser resumida na prática clínica centrada na doença.

Tendo sido feita essa conexão entre saúde e saúde mental, passamos, na sequência, a apresentar os conteúdos relacionados ao tema "Saúde mental na percepção dos trabalhadores", abordando as percepções dos trabalhadores sobre saúde mental, os fatores que a promovem ou dificultam e como o trabalhador busca por sua saúde mental. 


\section{Aspectos subjetivos da saúde mental}

A saúde mental, diferentemente da física, não foi considerada em termos materiais. Ao contrário, foi considerada como uma busca constante que se situa "além da comida e da bebida" (T08) e das necessidades básicas, tendo-se aqui o campo do desejo. A saúde mental também esteve relacionada ao bem-estar; a sentir-se bem no ambiente em que se estiver, com os outros e consigo mesmo; à capacidade de refletir e de mudar a opinião; à capacidade de lidar com situações adversas; e à habilidade de encontrar equilíbrio. Tal percepção vai ao encontro da noção ampliada de saúde mental, em que cada indivíduo busca pelo seu estado de bem-estar e pela capacidade de enfrentar o estresse inerente à vida (World Health Organization, 2005), especialmente no ambiente de trabalho.

Tem trabalho que é mais adoecedor. Tem trabalho que não, porque a gente consegue lidar bem com as outras pessoas e o trabalho não exige tanto, enfim... (T02).

Contudo encontrou-se um ponto de conflito no grupo, que considerou mais difícil falar de saúde mental do que de saúde, pois a doença mental "tu não vês, não é uma coisa física, que nem uma dor na coluna, não tem exames que possam comprovar que tu estás com depressão ou que tenha esquizofrenia" (T09). Entendemos que essa percepção é integrante da sociedade de modo geral e tem suas raízes no cientificismo, em que aquilo que não é visto, medido e objetivo não pode ser provado.

\section{Aspectos sociais da saúde mental}

Quanto aos aspectos sociais, os trabalhadores se referiram principalmente ao preconceito social, tanto da sociedade diante do doente quanto dele em relação à sua doença, não a aceitando muitas vezes. “Então, a saúde mental está muito como uma coisa meio preconceituosa também, porque as pessoas acham que quem vai no psiquiatra, no psicólogo, é louco" (T09).

A discriminação pode assumir várias formas e afetar diversas áreas da vida, como acesso ao tratamento e atenção adequados, emprego, educação e moradia. A dificuldade de manter relações sociais pode aumentar o isolamento, acentuando o transtorno mental; além disso, políticas que aumentem ou ignorem a discriminação associada ao transtorno mental podem agravar essa situação. O próprio governo pode discriminar pessoas com transtorno mental no que diz respeito aos direitos civis - votar, dirigir automóvel, possuir imóvel, direitos à reprodução sexual, casamento e benefícios socioeconômicos (Organização Mundial da Saúde, 2005). 
Além da questão do preconceito, os aspectos sociais também foram relacionados com processos de equilíbrio. Segundo os trabalhadores, algumas pessoas alcançam a condição de equilíbrio sozinhas; outras, contudo, necessitam de ajuda. Para eles, é por meio do equilíbrio psíquico que o sujeito conseguirá sair de situações conflitivas, conseguirá conviver "porque conviver implica relações que são difíceis muitas vezes!" (T02).

Para Dejours (1992), as situações de sofrimento possibilitam um movimento, uma ação que pode resultar em adoecimento, mas também em solução criativa. Desse modo, a perturbação no estado de saúde e saúde mental pode representar a criação de novos meios de enfrentamento, pois "para haver o equilíbrio tem que ter o desequilíbrio; a gente está em constante equilíbrio e desequilíbrio" (T04).

\section{O que promove a saúde e a saúde mental}

Os fatores que promovem a saúde e a saúde mental na percepção dos trabalhadores são manter um bom padrão de sono; estar descansado física e mentalmente; ter boas condições de vida; boa qualidade de vida; acesso à educação, à saúde, à moradia, à alimentação; investimento afetivo no sujeito; capacidade de resiliência; equilíbrio, apesar das dificuldades; e prevenção.

\footnotetext{
Algumas vezes tu olhas uma adversidade, uma coisa que tu não vais dar nada, por exemplo, o que o fulano vai ser quando crescer, e, quando tu vês, vem um poder de resiliência, de transformação. Tem tantos casos que a gente vê! (T08).
}

Aí eu acho que entra a questão da prevenção em que a gente não pensa tanto... não é educado desde cedo a pensar, assim como na saúde, na saúde do outro, do meio ambiente... (T08).

Prevenção e promoção fazem parte do trabalho em saúde. A prevenção está relacionada a doenças e divide-se em três níveis: no primeiro, busca-se evitar, detectar e prevenir o desenvolvimento de doenças; no segundo, são realizados diagnósticos e tratamentos precoces; no terceiro, procede-se ao tratamento e à reabilitação (Brasil, 2007).

Já a promoção relaciona-se com multifatores, como qualidade de vida, bem-estar, relação do sujeito com o seu ambiente social e familiar, trabalho, educação, saúde, habitação, renda, lazer. A promoção de saúde, em especial, é de extrema relevância para a reorientação de modelos assistenciais, pois objetiva a melhoria na qualidade de vida e a redução dos riscos à saúde por meio da elaboração de políticas públicas adequadas à condição de vida da população (Brasil, 2007). 
Prevenção relaciona-se com doença e promoção com saúde. Contudo, na prática dos serviços de saúde os limites dessas duas ações não são claros, pelo contrário, sobrepõem-se, complementando um ao outro. Ocorre, porém, que muitas vezes a atenção fica centrada na prevenção, deixando-se de considerar a promoção. Nesse caso, os participantes fazem menção à prevenção, contudo, tendo em vista os demais aspectos citados por eles - qualidade de vida, acesso, investimento afetivo, capacidade de resiliência - a promoção faz-se incluída.

\section{O que dificulta a saúde e a saúde mental}

Quanto aos fatores que podem dificultar a condição de saúde e saúde mental, o grupo identificou não ter as necessidades básicas atendidas; preocupações; falta de boa perspectiva social e familiar; falta de suporte familiar e de aposta no sujeito; pouca sensibilidade; sentir-se pressionado a estar produzindo, a ser um bom profissional, a ser bem-sucedido, a ser bom pai/mãe e a estar bem e feliz sempre.

$\mathrm{Eu}$, agora, trabalho na saúde, mas já trabalhei muito com adolescente, pré-adolescente e me deparei muito com a falta de perspectiva e o quanto isso abala o desenvolvimento. Acho que isso está muito relacionado não só com a questão familiar, mas com a questão social, que é muito ampla (T04).

Só que a gente vê, assim, quantas casas que visitamos, dos nossos pacientes, e a gente chega lá e é uma miséria, é algo que tu olhas, é um absurdo... (T05).

Cabe ressaltar que os trabalhadores falam aqui não somente sobre o que prejudica a saúde mental no trabalho, mas também fora dele, de modo dialético. Falam de aspectos físicos, sociais, psíquicos e ambientais. Destacamos a menção feita à família não dar suporte ou não ter uma aposta no sujeito. Conforme Winnicott (1983), a família é o primeiro e o principal campo social no qual uma criança está inserida e do qual depende. Se esse meio não lhe confere reconhecimento ou investe cuidado nela, pode haver um prejuízo de sua condição de saúde e de saúde mental que repercutirá na vida adulta.

Outro aspecto que destacamos é o fato de o sujeito se sentir pressionado em vários âmbitos da vida, bem como sentir-se exigido a estar bem sempre e como isso é salientado pela mídia:

A mídia passa que tu tens que estar feliz sempre, tu tens que estar em alta sempre. E é importante a gente ter momentos assim que está mais triste, não que a gente vá possibilitar isso, mas quando está presente, que se permita passar por aquele momento (T04). 
Quanto a isso, consideramos essencial destacar uma passagem de Notas sobre a experiência e o saber de experiência, de Jorge Larrosa Bondía (2002), que, ao falar dos tempos modernos e de como os sujeitos (não) são tocados pela experiência, diz:

O sujeito da experiência (...) é um sujeito alcançado, tombado, derrubado. Não um sujeito que permanece sempre em pé, ereto, erguido e seguro de si mesmo; não um sujeito que alcança aquilo que se propõe ou que se apodera daquilo que quer; não um sujeito definido por seus sucessos ou por seus poderes, mas um sujeito que perde seus poderes precisamente porque aquilo de que faz experiência dele se apodera. Em contrapartida, o sujeito da experiência é também um sujeito sofredor, padecente, receptivo, aceitante, interpelado, submetido. Seu contrário, o sujeito incapaz de experiência, seria um sujeito firme, forte, impávido, inatingível, erguido, anestesiado, apático, autodeterminado, definido por seu saber, por seu poder e por sua vontade (Bondía, 2002, p. 25).

\section{Estratégias encontradas pelos trabalhadores para desenvolver e manter a saúde mental}

As estratégias encontradas pelos trabalhadores em prol da saúde mental podem ser divididas em três grupos, conforme sua qualidade: as atividades artísticas, como pintar e desenhar; o lazer, como ir ao cinema ou ver um filme, ir ao teatro, cozinhar, fugir da rotina, viajar com a família, sair, convidar um colega para um café ou para fazer algo; e a atividade física, como pedalar, caminhar, fazer academia. Além desses grupos, os trabalhadores também mencionaram 'fazer terapia' como estratégia para a saúde mental. Tais estratégias, segundo os participantes, equilibram, ajudam, renovam, animam, recompõem a energia, proporcionam prazer e bem-estar, permitindo que se descarreguem as energias do trabalho.

Quando eu fico muito tempo sem produzir, produzir arte, [quando] eu penso em desenhar ou pintar, me dá uma renovada, me anima, me dá um prazer, faz bem para mim, me dá um ajustamento, isso além de poder fazer terapia também, poder se tratar. Isso é bem importante, porque a gente está lidando com a saúde mental do outro. (T08).

E daí, para a minha saúde, eu vou para a escola, eu faço atividades com as crianças, eu corro com eles, eu brinco de esconde-esconde com eles, eu faço atividades assim... Daí, descarrego as energias que, digamos, que eu carrego daqui... E, digamos, minha saúde mental fica bem, me sinto bem de novo. Cada um encontra uma coisa, não é? (T17).

Estudo de Sessa et al. (2008) sobre a influência do ambiente de trabalho no desempenho e desgaste dos profissionais indica que o cotidiano das 
equipes de saúde e de saúde mental coloca os trabalhadores em contato com o sofrimento, a dor e até mesmo a morte. Trabalhar, pois, com tais aspectos causa desgaste emocional que, somado à pressão exercida por esse tipo de trabalho, cria um campo propício para estresse e depressão.

Isso se correlaciona com a noção de carga psíquica do trabalho, exposta por Dejours (1994), a qual faz parte da subjetividade de cada sujeito e é vivenciada em seu trabalho diário. Compõe-se de elementos afetivos e relacionais e representa o reflexo, no trabalhador, da pressão que constitui a organização do trabalho. Segundo o autor, quando o trabalhador não mais consegue conciliar o impasse entre o trabalho e o psiquismo, ou quando a energia psíquica não pode ser descarregada no exercício do trabalho, essa energia se acumula no aparelho psíquico, aumenta a tensão e gera desprazer.

A descarga dessa energia pode ocorrer mediante três vias: a psíquica, a motora ou a visceral (Dejours, 1994). A via psíquica de descarga caracteriza-se pela produção de representações mentais, como fantasias de agressividade. A via motora, utilizada quando a anterior não se faz satisfatória, inclui um vasto repertório motor ou comportamental que pode ser utilizado pelo indivíduo de modo a descarregar sua tensão. Já a via visceral se faz presente quando da impossibilidade de utilizar as vias anteriores, sendo caracterizada pela atuação do sistema nervoso autônomo e pelo desordenamento das funções somáticas. Cada trabalhador, de acordo com a sua história de vida e a sua estrutura de personalidade, terá vias de descarga preferenciais, as quais não serão as mesmas entre os todos os trabalhadores. Se nada for feito, ou se nada do que for feito tiver resultado positivo, então a fadiga ou o sofrimento poderão desencadear uma patologia.

Pelo que pudemos observar, nesse grupo de trabalhadores, o meio encontrado para descarga de energia é o motor, pois cada uma das atividades referidas em favor da saúde mental inclui movimento, o ato de fazer algo. Entendemos disso que os trabalhadores têm conseguido conciliar o trabalho com os demais campos da vida, visto que são empreendidas atividades extratrabalho, mas que têm influência positiva nele. É nesse sentido que Dejours (1992) nos adverte que o sofrimento oriundo do trabalho nem sempre é patogênico, mas pode ser criativo, na medida em que o sujeito crie soluções que favoreçam o estado de saúde. Nesse caso, as estratégias defensivas dão conta do sofrimento psíquico e possibilitam prazer.

\section{Considerações finais}

Como principais resultados, destacamos que a noção de saúde se encontra relacionada com condições materiais, prevenção (diretamente) e promoção (indiretamente). Já a saúde mental está mais ligada ao campo afetivo. 
Contudo, pode-se observar uma tendência a integrar todos os aspectos relativos à saúde e à saúde mental, bem como a noção de que o sujeito não se encontra dividido em partes. As estratégias para o desenvolvimento e a manutenção da saúde mental são relacionadas com o movimento, com fazer algo, ou seja, passam pelo corpo. Além disso, ao longo da discussão, pode-se perceber que as falas se alternam entre descrições sobre saúde e saúde mental do próprio trabalhador e sobre o seu trabalho, o que também representa uma tendência à integração.

A palavra de maior destaque, por estar presente em quase todas as subcategorias temáticas, foi equilíbrio. Compreendemos que os trabalhadores se utilizaram de equilíbrio para representar a saúde e a saúde mental não como um conceito estático, mas sim como um estado que resulta da solução de uma situação conflitiva. Reconhecem ser necessária certa dose de instabilidade para que possa haver questionamento, mudança, sofrimento ou satisfação. O equilíbrio, portanto, só pode surgir do desequilíbrio, e é uma ação em constante dialética.

Podemos inferir que, nesse momento, a equipe está em busca de novos modelos de atenção e de diálogo em conexão com a reforma psiquiátrica. Desse modo, consideramos fundamental um espaço de escuta e atenção aos trabalhadores, pois é a partir da reflexão sobre seu fazer e sobre conceitos relacionados a seu fazer que o trabalhador se torna agente de seu processo de trabalho em saúde e em saúde mental, no qual é figura essencial.

Esperamos que este trabalho tenha destino prático e não somente acadêmico, na medida em que possa estimular outras atividades semelhantes pelos trabalhadores, gestores e pesquisadores. Compreendemos que o campo da saúde mental está em processo de desinstitucionalização de antigos paradigmas por novos. Contudo, isso não se faz de forma externa ou alheia aos sujeitos, mas sim deve partir deles. Cabe observar, no entanto, que não é possível qualquer tipo de mudança se as próprias pessoas não as compreenderem ou não entenderem porque as realizam.

\section{Colaboração}

As autoras declaram que ambas tiveram participação em todas as etapas que se referem à construção do artigo. 
Resumen Este artículo trata de un estudio prospectivo y descriptivo de enfoque cualitativo que investigó, por medio de un grupo focal, las percepciones que los trabajadores de un Centro de Atención Psicosocial para Niños y Adolescentes, CAPSi (en portugués), en el interior del estado de Río Grande do Sul, Brasil, tienen sobre salud y salud mental. El marco teórico se basa en la psicodinámica del trabajo de Christophe Dejours, en las políticas y directrices del Ministerio de Salud y en los conceptos de salud y salud mental propuestos por la Organización Mundial de la Salud. El material fue analizado por codificación temática, en base al enfoque de la estructura. Como principales resultados se destacan la capacidad de resolver situaciones conflictivas y la realización de alguna actividad corporal como estrategias de mantenimiento de la salud y la salud mental, así como la comprensión integrada de salud entre aspectos físicos, psíquicos y sociales.

Palabras clave salud, salud mental, salud mental del trabajador, CAPSi.

\section{Notas}

1 Universidade Federal de Santa Maria, Santa Maria, Rio Grande do Sul, Brasil.

$<$ juliane.caeran@yahoo.com>

Correspondência: Rua Venâncio Aires, n. 1.476, ap. 107, Santa Maria, RS, Brasil. CEP 97010-002.

2 Centro Universitário Ritter dos Reis, Cristal, Porto Alegre, Rio Grande do Sul, Brasil. <ckzogbi@gmail.com>

3 "a state of complete physical, mental and social well-being and not merely the absence of disease or infirmity" (World Health Organization, 2005, p. 2).

4 Este artigo é resultado de um subprojeto intitulado “O trabalhador em saúde mental infantil: sentimentos e saúde", vinculado ao projeto guarda-chuva "Proconvive - projeto de implantação do espaço de convivência permanente para crianças usuárias do CAPS infantil da cidade de Santa Maria, Rio Grande do Sul, e avaliação do impacto da intervenção terapêutica em usuários e funcionários do CAPSi". O referido projeto guarda-chuva conta com o apoio financeiro da Fundação de Apoio à Pesquisa do Rio Grande do Sul (Fapergs), por meio do edital Fapergs PPSUS 02/2009, sob n. de processo 0900982. 


\section{Referências}

BONDÍA, Jorge L. Notas sobre a experiência e o saber de experiência. Revista Brasileira de Educação, São Paulo, n. 19, p. 20-28, 2002.

BRANT, Luiz C.; MINAYO-GOMEZ, Carlos. A transformação do sofrimento em adoecimento: do nascimento da clínica à psicodinâmica do trabalho. Ciência \& Saúde Coletiva, Rio de Janeiro, v. 9, n. 1, p. 213-223, 2004.

BRASIL. Ministério da Saúde. Portaria n. 336/GM, de 19 de fevereiro de 2002. Define e estabelece diretrizes para o funcionamento dos Centros de Atenção Psicossocial. Diário Oficial da União, Brasília, DF, 20 fev. 2002. Seção 1, p. 22.

BRASIL. Ministério da Saúde. Secretaria de Atenção à Saúde. Departamento de Ações Programáticas Estratégicas. Saúde mental no SUS: os centros de atenção psicossocial. Brasília: Ministério da Saúde, 2004.

BRASIL. Ministério da Saúde. Secretaria de Atenção à Saúde. Departamento de Ações Programáticas Estratégicas. Coordenação Geral de Saúde Mental. Reforma psiquiátrica e politica de saúde mental no Brasil. In: CONFERÊNCIA REGIONAL DE REFORMA DOS SERVIÇOS DE SAÚDE MENTAL: 15 ANOS DEPOIS DE CARACAS. Anais... Brasília: Opas, novembro de 2005.

BRASIL. Ministério da Saúde. Agência Nacional de Saúde Suplementar (ANS). Promoção da saúde e prevenção de riscos e doenças na saúde suplementar: manual técnico. Rio de Janeiro: ANS, 2007.

BRASIL. Ministério da Saúde. Secretaria de Atenção à Saúde. Política Nacional de Humanização da Atenção e Gestão do SUS. Clínica ampliada e compartilhada. Brasília: Ministério da Saúde, 2009.

BUSS, Paulo M.; PELLEGRINI FILHO, Alberto. A saúde e seus determinantes sociais. Physis: Revista de Saúde Coletiva, Rio de Janeiro, v. 17, n. 1, p. 77-93, 2007.
CAMPOS, Célia M. S.; SOARES, Cássia B. A produção de serviços de saúde mental: a concepção de trabalhadores. Ciência \& Saúde Coletiva, Rio de Janeiro, v. 8, n. 2, p. 621628,2003

DEJOURS, Christophe. A loucura do trabalho: estudo de psicopatologia do trabalho. 5. ed. São Paulo: Cortez, 1992.

DEJOURS, Christophe. A carga psíquica do trabalho. In: DEJOURS, Christopher; ABDOUCHELI, Elisabeth; JAYET, Christian. Psicodinâmica do trabalho: contribuições da escola dejouriana à análise da relação prazer, sofrimento e trabalho. São Paulo: Atlas, 1994. p. 21-32.

DEJOURS, Christophe; ABDOUCHELI, Elisabeth. Itinerário teórico em psicopatologia do trabalho. In: DEJOURS, Christopher; ABDOUCHELI, Elisabeth; JAYET, Christian. Psicodinâmica do trabalho: contribuições da escola dejouriana à análise da relação prazer, sofrimento e trabalho. São Paulo: Atlas, 1994. p. 87-99.

FLECK, Marcelo P. A. et al. Aplicação da versão em português do instrumento abreviado de avaliação da qualidade de vida "WHOQOL-bref". Revista de Saúde Pública, São Paulo, v. 34, n. 2, p. 178-183, 2000.

FLICK, Uwe. O desenho da pesquisa qualitativa. Porto Alegre: Artmed, 2009.

GIBBS, Graham. Análise de dados qualitativos. Porto Alegre: Artmed, 2009.

HENNINGTON, Élida A. Gestão dos processos de trabalho e humanização em saúde: reflexões a partir da ergologia. Revista de Saúde Pública, São Paulo, v. 42, n. 3, p. 555-561, 2008.

KITZINGER, Jenny. Grupos focais com usuários e profissionais da atenção à saúde. In: POPE, Catherine; MAYS, Nicholas. Pesquisa qualitativa na atenção à saúde. 2. ed. Porto Alegre: Artmed, 2006. p. 87-99. 
MINAYO, Maria C. S. O desafio do conhecimento: pesquisa qualitativa em saúde. 10. ed. São Paulo: Hucitec, 2007.

ORGANIZAÇÃO MUNDIAL DA SAÚDE(OMS). Departamento de Saúde Mental e Abuso de Substâncias. Livro de recursos da OMS sobre saúde mental, direitos humanos e legislação. Brasília: Organização Mundial de Saúde, 2005.

POPE, Catherine; MAYS, Nicholas. Pesquisa qualitativa na atenção à saúde. 2. ed. Porto Alegre: Artmed, 2006.

POPE, Catherine; ZIEBLAND, Sue; MAYS, Nicholas. Analisando dados qualitativos. In: POPE, Catherine; MAYS, Nicholas. Pesquisa qualitativa na atenção à saúde. 2. ed. Porto Alegre: Artmed, 2006. p. 87-99.

SANTOS, Ana F. O.; CARDOSO, Carmen L. Profissionais de saúde mental: manifestação de stress e burnout. Estudos de Psicologia, Campinas, v. 27, n. 1, p. 67-74, jan.-mar. 2010.

SCLIAR, Moacyr. História do conceito de saúde. Physis: Revista de Saúde Coletiva, Rio de Janeiro, v. 17, n. 1, p. 29-41, 2007.

SESSA, Roberta M. et al. Influência do ambiente laboral no desempenho e desgaste profissional da equipe de saúde. Revista de Administração em Saúde, São Paulo, v. 10, n. 39, p. 51-60, abr.- jun., 2008.
SILVA, Elisa A.; COSTA, Ileno I. Saúde mental dos trabalhadores em saúde mental: estudo exploratório com os profissionais dos Centros de Atenção Psicossocial de Goiânia/ GO. Psicologia em Revista, Belo Horizonte, v. 14, n. 1, p. 83-106, jun. 2008.

STRAUB, Richard O. Psicologia da saúde. Porto Alegre: Artmed, 2005.

WINNICOTT, Donald W. O ambiente e os processos de maturação. Porto Alegre: Artes Médicas, 1983.

WORLD HEALTH ORGANIZATION (WHO). Promoting Mental Health: Concepts, Emerging Evidence, Practice. Report of the World Health Organization, Department of Mental Health and Substance Abuse in collaboration with the Victorian Health Promotion Foundation and the University of Melbourne. Genebra: WHO, 2005. Disponível em: <www. who.int/mental_health/evidence/MH_ Promotion_Book.pdf $>$. Acesso em: 16 maio 2011.

Recebido em 26/11/2012

Aprovado em 13/03/2014 